\title{
Construal of Mental Health Problems in English Learners' Dictionaries
}

\author{
Arleta Adamska-Sałaciak, Faculty of English, \\ Adam Mickiewicz University, Poznań, Poland (arleta@amu.edu.pl)
}

\begin{abstract}
The purpose of the present study is to check how well monolingual learners' dictionaries cope with the sensitive field of mental ill health. The subject is considered worthy of attention in view of the high prevalence of mental health problems among young people, at whom learners' dictionaries are primarily targeted. To obtain a picture of the situation, twelve names of common mental health issues have been looked up in six learners' dictionaries of English (five British and one American). The analysis zoomed in on the choice of genus words, the information value of the definitions and examples, and the potential impact of both on the sensibilities of dictionary users. To resolve occasional disagreements in matters of content, specialist medical sources have been consulted. The treatment is cognitive linguistic in spirit, with the notion of construal - specifically its key component of focal adjustment — serving as the main descriptive tool.
\end{abstract}

Keywords: CONSTRUAL, COGNITIVE LINGUISTICS, MENTAL HEALTH, MONOLINGUAL ENGLISH LEARNERS' DICTIONARIES, DEFINITIONS, EXAMPLES

Opsomming: Die konstruering van geestesgesondheidsprobleme in Engelse aanleerderswoordeboeke. Die doel van hierdie studie is om te bepaal hoe goed eentalige aanleerderswoordeboeke die sensitiewe veld van geestesongesteldheid hanteer. In die lig van die hoë voorkoms van geestesgesondheidsprobleme onder jongmense, op wie aanleerderswoordeboeke primêr gerig is, verdien hierdie onderwerp aandag. Om 'n oorsig van hierdie situasie te verkry, is twaalf name van algemene geestesgesondheidskwessies in ses Engelse aanleerderswoordeboeke (vyf Brits en een Amerikaans) nageslaan. Die analise het gefokus op die keuse van verwante woorde, die inligtingswaarde van die definisies en voorbeelde, en die potensiële impak wat beide op die sensitiwiteite van woordeboekgebruikers kan hê. Om inhoudelike verskille wat soms voorkom, op te los, is spesialis- mediese bronne geraadpleeg. Die hantering is oorwegend kognitief taalkundig van aard, met die begrip van konstruering - met spesifiek die sleutelkomponent van fokusaanpassing — wat as die belangrikste deskriptiewe hulpmiddel dien.

Sleutelwoorde: KONSTRUERING, KOGNITIEWE LINGUISTIEK, GEESTESGESONDHEID, EENTALIGE ENGELSE AANLEERDERSWOORDEBOEKE, DEFINISIES, VOORBEELDE

\section{Rationale}

Scholars have long been alert to the dangers of dealing insensitively with sensitive lexicographic material. Their attention has focused predominantly on 
headwords connected with race, ethnicity, ideology, religion, gender, and age (e.g., Kachru and Kahane 1995, Murphy 1998, Swanepoel 2005, Moon 2014). Recently, Norri (2018 and 2020) added two studies relating to the field of medical practice, illness, and disability. In the present paper, I would like to look at some terms connected with mental ill health which, arguably, present an even greater challenge, if only because of the stigma they still carry in most societies. ${ }^{1}$

According to media reports, ${ }^{2}$ the proportion of young people all over the world suffering from a variety of mental disorders keeps growing alarmingly. Given that monolingual English learners' dictionaries (MELDs) are available globally and are consulted predominantly by young people, it makes sense to ask how well they deal with the topic. Of course, a general-purpose dictionary is not the obvious go-to resource for mental health problems, but it is certainly one of the options.

\subsection{Theoretical background}

Meaning does not come ready-made, but has to be (re)constructed in the process of communication. This view, widely accepted within the humanities, has been argued for most forcefully by linguists, especially those of the cognitive persuasion. No matter which cognitive linguistic model we consult - e.g., Langacker's Cognitive Grammar, Fauconnier and Turner's Mental Spaces, Fillmore's Frame Semantics, Evans' Access Semantics - one of the pivotal ideas seems to be that individual linguistic expressions are no more than underdetermined prompts for rich meaning construction. As put by Evans (2019: 500), "linguistic expressions have meaning potential. Rather than 'encoding' meaning, [they] represent partial building instructions" from which meaning is constructed by the speaker/writer and then reconstructed by the listener/reader.

That individual linguistic expressions have meaning potentials rather than fully determined meanings is, of course, recognized also by linguistically sophisticated lexicographers (notably Hanks, e.g., 2013). Cognitive linguists, however, go a step further in that they pay special attention to how the speaker/writer 'packages' the elements to be assembled by the addressee, i.e., to what Langacker has christened construal. Resulting from our "ability to conceive and portray the same situation in alternative ways" (Langacker 2013: 445), construal is the process "whereby a linguistic expression draws upon aspects of encyclopaedic knowledge, in giving rise to a context-specific interpretation" (Evans 2019: 353). As a result, meaning is a function of both content and construal (Langacker 2000: 9). Alternative construals of the same content are always possible and no construal is ever 'correct'.

Construal focuses attention on different aspects of a scene, an operation that, by analogy with visual perception, Langacker calls focal adjustment. The adjustment is achieved by a variety of means, both lexical (e.g., the use of came versus went, or foliage versus leaves) and grammatical (e.g., the use of active ver- 
sus passive, perfective versus imperfective, or a verb versus a nominalization). Focal adjustments may vary according to three parameters: selection, perspective, and abstraction (Langacker 1987). The first of these selects the domain against which a scene is construed and the entities participating in the scene. A single linguistic unit of semantic structure is typically structured by multiple conceptual domains which together form a domain matrix. In the case of the concepts investigated here, such a matrix might include, for instance, the conceptual domains of HEALTH (ILLNESS?), MIND, BEHAVIOUR, MOOD, EMOTION, or NORM. Translated into lexicographical practice, this means that a dictionary definition will situate the condition denoted by a particular headword within one of the domains (or their cross-section) by virtue of selecting the genus, such as, for example, mental illness or emotional disorder. Participants in the scene, in turn, may be associated with the choice of the differentiae, indicating which aspects of encyclopaedic (here: specialist medical) knowledge about a given condition are considered essential. Additional information can be gleaned from a dictionary's cross-references to other entries. In the online dictionaries examined, entries are frequently cross-referred to more general, thesaurus-type sections, whose names (e.g., Mental and psychiatric disorders) provide extra clues as to how a particular concept is construed.

The second parameter of focal adjustment, perspective, is responsible, among other things, for the distinction between subjective and objective construal. As a rule, both the speaker/writer and the addressee are construed subjectively (or offstage, to use the theatre metaphor proposed by Langacker). In objective construal, by contrast, one or both of them are placed onstage. This is achieved mainly through the use of deictics. When it comes to dictionary definitions, it is the reliance on second person pronouns (you, your, yourself) that construes the dictionary user as a participant in the scene, putting them onstage - an unenviable place to be in the context of mental health issues.

The last parameter, abstraction, involves the ability to conceive a situation at varying levels of schematization (Langacker 2002: 291), regulating the amount of detail given. In a dictionary definition of a medical issue, this will be realized, again, through the differentiae, thereby reflecting the lexicographer's view of how much encyclopedic information about a particular condition needs to be presented in a general-purpose dictionary.

My working assumption is that the lexicographers working on MELDs have roughly comparable knowledge regarding common mental health issues. The content of what they define will thus be more or less the same, but the construal most likely will not. Construal being largely invisible (Langacker 2000: 71), it takes some work to try and make it (more) visible. The present paper attempts to do just that, albeit on a very small scale and with reference to a very specific type of text. The belief that such an undertaking is not only feasible but also worthwhile comes, at least in part, from the steadily growing amount of work in cognitive stylistics (see, e.g., Hart 2019). The results of such stylistic 
studies have demonstrated that cognitive linguistics offers tools - of which construal is but one - for analyzing all kinds of texts, not just literature.

\subsection{Materials and method}

Twelve lexemes from the field of poor mental health have been looked up in the free online versions of six MELDs: five British (CALD, COBUILD, LDOCE, MED, OALD) and one American (MW). In order to check the validity of the author's understanding of a particular condition against state-ofthe-art expert knowledge, a guidebook to the Diagnostic and Statistical Manual of Mental Disorders (Black and Grant 2014) has been consulted whenever necessary, as have recent print editions of the nine medical dictionaries listed in the References.

In addition to the umbrella term mental illness, most of the lexemes chosen for analysis are names of conditions, both general (anxiety disorder, eating disorder) as well as more specific (agoraphobia, anorexia, claustrophobia, bulimia, depression, $O C D$, orthorexia). The remaining two terms (panic attack, self-harm) have been included on the grounds of the high prevalence of the symptoms they denote.

The main analytic focus is the entries' information content. Since allowances must be made for the restrictions imposed on definition writers by controlled defining vocabularies, less attention has been paid to the degree of definitional precision than to the consistent choice of genus words, the informative value and appropriateness of examples, and the possible connotations carried by both examples and definitions (including their potential to upset, offend, or alienate the user).

\section{Analysis}

\subsection{Quantitative}

As is evident from Table 1, two dictionaries, CALD and MED, feature all the entries we are interested in. Seven of the twelve entries (depression, obsessivecompulsive disorder/OCD, agoraphobia, claustrophobia, eating disorder, anorexia, bulimia) are present in all six dictionaries, one (self-harm) is included in five, another one (orthorexia) in four, and three (mental illness, anxiety disorder, panic attack) in two dictionaries. This is not a bad result, especially when compared with the coverage of the same terms in medical dictionaries, as summarized in Table $2{ }^{5}$ None of the latter has orthorexia (which, incidentally, is absent also from DSM-5) and only one features self-harm (which DSM-5 lists as a newly proposed disorder under the category Conditions for Further Study). Thus, when it comes to phenomena which have entered public discourse relatively recently, ${ }^{6}$ MELDs actually do better than medical dictionaries. This is hardly 
surprising. After all, before being able to include any given term in a specialist dictionary, its authors have to wait for the relevant official body to approve the term, together with its associated concept, as part of the discourse of their discipline.

Table 1: Coverage of entries denoting mental health issues in MELDs

\begin{tabular}{|l|l|l|l|l|l|l|l|l|l|l|l|l|}
\hline & $\begin{array}{l}\text { mental } \\
\text { illness }\end{array}$ & depression & $\begin{array}{l}\text { anxiety } \\
\text { disorder }\end{array}$ & $\begin{array}{l}\text { OCD (or } \\
\text { full form })\end{array}$ & $\begin{array}{l}\text { agora- } \\
\text { phobia }\end{array}$ & $\begin{array}{l}\text { claustro- } \\
\text { phobia }\end{array}$ & $\begin{array}{l}\text { panic } \\
\text { attack }\end{array}$ & $\begin{array}{l}\text { eating } \\
\text { disorder }\end{array}$ & $\begin{array}{l}\text { anorexia } \\
\text { (nervosa) }\end{array}$ & bulimia & orthorexia & self-harm \\
\hline CALD & + & + & + & + & + & + & + & + & + & + & + & + \\
\hline COBUILD & - & + & - & + & + & + & - & + & + & + & - & + \\
\hline LDOCE & - & + & - & + & + & + & - & + & + & + & + & + \\
\hline MED & + & + & $\begin{array}{l}\text { generalized } \\
\text { a.d. }\end{array}$ & + & + & + & + & + & + & + & + & + \\
\hline OALD & - & + & - & + & + & + & - & + & + & + & + & + \\
\hline MW & - & + & - & + & + & + & - & + & + & + & - & - \\
\hline
\end{tabular}

Table 2: Coverage of entries denoting mental health issues in medical dictionaries

\begin{tabular}{|c|c|c|c|c|c|c|c|c|c|c|c|c|}
\hline & $\begin{array}{l}\text { mental } \\
\text { illness }\end{array}$ & depression & $\begin{array}{l}\text { anxiety } \\
\text { disorder }\end{array}$ & $\begin{array}{l}\mathrm{OCD} \text { (or } \\
\text { full form) }\end{array}$ & $\begin{array}{l}\text { agora- } \\
\text { phobia }\end{array}$ & $\begin{array}{l}\text { claustro- } \\
\text { phobia }\end{array}$ & $\begin{array}{l}\text { panic } \\
\text { attack }\end{array}$ & $\begin{array}{l}\text { eating } \\
\text { disorder }\end{array}$ & $\begin{array}{l}\text { anorexia } \\
\text { (nervosa) }\end{array}$ & bulimia & orthorexia & self-harm \\
\hline Black's & + & + & $\begin{array}{l}\text { a. neurosis/ } \\
\text { state }\end{array}$ & + & + & + & + & + & + & + & - & - \\
\hline Collins & - & + & $\begin{array}{l}\text { under } \\
\text { anxiety }\end{array}$ & + & + & + & + & - & + & + & - & - \\
\hline DoMT & + & + & + & + & + & + & + & + & + & + & - & + \\
\hline Dorland's & m. disorder & + & + & + & + & + & p. disorder & + & + & + & - & - \\
\hline Melloni's & + & + & - & + & + & + & - & - & + & + & - & - \\
\hline Mosby's & + & + & + & + & + & + & + & + & + & + & - & - \\
\hline Stedman's & + & + & + & + & + & + & + & + & + & + & - & - \\
\hline Taber's & $\begin{array}{l}\text { under } \\
\text { illness }\end{array}$ & + & + & + & + & + & p. disorder & + & + & + & - & - \\
\hline Webster's & + & + & + & + & + & - & + & - & + & + & - & - \\
\hline
\end{tabular}

\subsection{Qualitative}

\section{MENTAL ILLNESS}

As might be expected, none of the MELDs has an entry for mental health issue, mental health problem or mental disorder, so mental illness seemed the obvious 
place to start. CALD and MED, the only two dictionaries that feature the entry, ${ }^{7}$ offer paraphrases ('an illness that affects the/someone's mind'). In LDOCE, a definition of mental illness can be gleaned from the entry for mentally ill: 'having an illness that affects your mind and your behaviour'. The mention of behaviour adds an important element to the definition, but the use of the second person pronoun, placing the reader onstage, is unfortunate. As we shall see, this is not the only headword in which objective construal is encountered.

\section{DEPRESSION}

How depression is viewed differs from one dictionary to the next. In addition to the expected ILLNESS, we also find the superordinate domains of STATE and CONDITION. The actual genus words are: mental illness (CALD), mental state (COBUILD), and medical condition (LDOCE, MED, MW, OALD). Mental illness, although not technically wrong, might be questioned on the grounds that it is a strong, possibly stigmatizing, description, so an argument could perhaps be made for reserving it for psychotic disorders. On the other hand, the somewhat vague mental state is not necessarily better, since it might be seen as downplaying the seriousness of depression. On balance, medical condition, especially when modified by serious (MW), seems the best description, not least because it carries an indirect promise that medicine can help the sufferer. This is not to say that it would satisfy everyone: many therapists would no doubt object to medical condition on the grounds that it implicitly privileges the biochemical aetiology of depression. However, such an objection would amount to hairsplitting if made with regard to a general-purpose dictionary.

Depression is the most polysemous item among those considered here. The uses we are interested in, that is, those pertaining to mental/emotional states, fall into two related categories: the medical one mentioned in the preceding paragraph versus the more everyday one - a deep feeling of sadness. Most dictionaries reflect that. CALD, MW and OALD offer two distinct senses: in CALD and MW the medical condition comes second, in OALD it is defined first. LDOCE and MED both present the two readings of depression as subsenses within one sense, but order them differently: LDOCE prioritizes the medical condition, while MED starts with the 'feeling of being extremely unhappy'. COBUILD alone does not acknowledge that depression may be used in two senses, defining it simply as '... a mental state in which you are sad and feel that you cannot enjoy anything, because your situation is so difficult and unpleasant'. This does not convey the idea of illness at all, nor does it allow for the possibility of endogenous depression, where the depressive state is somatic in origin rather than caused by external stressors (cf. Melloni's).

CALD, LDOCE, OALD, and MED, the dictionaries that do a reasonably good job of defining depression in the medical sense, offer some degree of detail (i.e., exhibit a low degree of abstraction) by specifying how a depressed person feels (CALD and LDOCE: 'very unhappy and anxious', MED: 'unhappy', 
OALD: 'very sad and anxious'). The CALD, LDOCE and OALD definitions thus seem marginally superior to the MED one in that they refer to anxiety, a frequent symptom of depression. Additionally, CALD, LDOCE and MED note that a depressed person is unable to lead a normal life, while OALD mentions 'physical symptoms such as being unable to sleep'.

COBUILD and LDOCE resort to objective construal. The COBUILD case has been quoted above; LDOCE says: 'a medical condition that makes you very unhappy and anxious and often prevents you from living a normal life'. It would have been just as easy to use someone or a person instead of you.

The examples on offer are mostly useful, often providing some insight into the social context of depression, e.g., CALD: Tiredness, loss of appetite, and sleeping problems are all classic symptoms of depression., Withdrawal is a classic symptom of depression.; MED: Some children show signs of anxiety and depression at exam time.; OALD: She suffered from severe depression after losing her job.; MW: Many people suffer from clinical depression for years before being diagnosed. LDOCE gives one example at the relevant sense (featuring post-natal depression) and seven more corpus examples, four of which can stand on their own.

\section{ANXIETY DISORDER}

Only CALD features the headword in this form. MED, the only other dictionary that covers the condition, redirects automatically to generalized anxiety disorder. The genus in both definitions is mental illness, one 'in which a person is so anxious that their normal life is affected' (CALD) or 'that causes someone to feel very anxious most of the time' (MED). MED's selection of differentiae is perhaps more suggestive of what it feels like to suffer from anxiety. It should also be noted that CALD includes NORM in the conceptual domain matrix. Reference to norms of any kind is always risky, since it implies abnormality, or at least non-conformity with the norm. In this case, however, it is not normality as such that is invoked, but a person's 'normal life', so the definition's potential for being interpreted as judgemental is relatively low.

The single example given in CALD (Panic attacks, irrational fears, and compulsive behaviour are examples of anxiety disorders.) is perfect. Mentioning compulsions as one of the manifestations of pathological anxiety is especially useful, since non-specialists may well be unaware of the link between the two. MED's example (People with symptoms of generalized anxiety disorder tend to always expect disaster.) also has some added value relative to the definition.

\section{OBSESSIVE-COMPULSIVE DISORDER (OCD)}

Two entries have been examined here: that for the full name of the condition and for the commonly used abbreviation. LDOCE and MW do not have obsessive-compulsive disorder, but both have entries for $O C D$ (where the abbreviation is expanded) and for the adjective obsessive-compulsive. The respective defini- 
tions in LDOCE are markedly different: the one for $O C D$ concentrates on the symptoms ('a person does the same thing again and again and cannot stop doing it'), while the one for the adjective goes some way towards explaining what lies behind a sufferer's behaviour ('they have strong anxious feelings'). MW has no definition under $O C D$; its definition of obsessive-compulsive features the genus mental illness, similarly to CALD, LDOCE, and MED. OALD opts for mental disorder. MW's differentiae consist of symptoms ('repeating actions or thinking about certain things too much'). It is also the only dictionary that explicitly mentions obsessive thoughts; the others limit themselves to compulsive actions. MED (which has obsessive-compulsive disorder and cross-refers OCD to it) and OALD (which does the opposite) both provide explanations of compulsive behaviour in terms of goals: 'in order to avoid painful thoughts' (MED) and 'to get rid of fears or unpleasant thoughts'(OALD). COBUILD restricts itself to behavioural rituals ('... cannot stop doing a particular thing, for example washing their hands'). CALD is the least helpful: its 'mental illness that causes a person to do something repeatedly for no reason' is at once simplistic and vague. No concrete symptoms are mentioned at all (by contrast, COBUILD, LDOCE, and MED all speak of hand-washing), nor is there any attempt at explaining why sufferers act the way they do. All dictionaries except MED ('a mental illness that makes you keep repeating an action...') manage to avoid objective construal.

Except for LDOCE's 'strong anxious feelings', no explicit connection is made anywhere between OCD and anxiety. This is regrettable, since most medical sources (Dorland's, Melloni's, Mosby's, Stedman's, Taber's, Webster's) treat $\mathrm{OCD}$ as a type of anxiety disorder. On the whole, after consulting medical dictionaries, the general impression is that MELDs tend to underplay the seriousness of the condition. Melloni's and Dorland's say that compulsions and obsessions 'interfere with personal or social functioning'; Mosby's that they 'significantly interfere with the patient's occupational, social, or interpersonal functioning'; Taber's that they 'interfere with effective living'. According to Collins Dictionary of Medicine, obsessive thoughts 'are so frequent and intrusive as to cause distress or disability' and '[t]here is often depression and sometimes suicide'. The popular stereotype of a compulsion, i.e., repetitive hand-washing, the only example on offer in some MELDs, may also unwittingly trivialize the condition. Perhaps the higher level of schematization in those dictionaries that do not mention any typical compulsive actions at all is a better solution.

Only LDOCE has full-sentence examples. Three of the four of them add valuable information to the definition (two are about the co-occurrence of OCD and anorexia, the third one mentions Prozac as an approved treatment).

\section{AGORAPHOBIA}

A different conceptual domain (FEAR) is selected here than for the headwords analyzed so far. Of course, the fact that the genus word in all six dictionaries is 
fear may result from purely etymological considerations, but it may also indicate that the referent is construed as a symptom rather than an illness in its own right. The latter interpretation would agree with Black's, according to which 'agoraphobia is a symptom of psychological disorder' [emphasis added], but not, e.g., with Mosby's, where it is treated in the same way as OCD, that is, as a type of anxiety disorder.

Five of the learners' dictionaries define agoraphobia as the fear of open or public spaces or places; only CALD transcends the etymology. After mentioning the basic 'fear of going outside and being in public places', it goes on: 'or of being in a situation from which it might be difficult to escape or in which help might not be available'. This is in line with current psychiatric wisdom. According to DSM-5 (Black and Grant 2014), agoraphobia may involve anxiety in response to finding oneself in an enclosed place, such as a theatre or a train. This means that agoraphobics sometimes present with symptoms traditionally associated with claustrophobia, which is also remarked upon in the Collins Dictionary of Medicine, albeit only in the claustrophobia entry. To the uninitiated, the comorbidity of agoraphobia and claustrophobia might seem paradoxical since, in popular understanding, agoraphobia and claustrophobia are antonyms, a fact reflected in the MELDs' cross-references (only COBUILD does not make the connection).

CALD gives two examples, one of which (Suffering from agoraphobia, she's afraid to even step outside her home.) appears to be constructed rather than corpus-based, but nonetheless adds detail to the definition. LDOCE has seven sentences in its Examples from the corpus section, two of which seem particularly informative: one accentuates the counterintuitive relationship between agoraphobia and claustrophobia mentioned above (It was agoraphobia but felt like claustrophobia.), while the other offers a clue as to the origins of agoraphobia, linking it with another common symptom (When some one can't cope with panic attacks, agoraphobia is often the consequence and treating this condition requires specialist help.) ${ }^{9}$ This agrees with Stedman's, which says that agoraphobia is 'often associated with panic attacks'.

\section{CLAUSTROPHOBIA}

The domain selected is, again, predominantly FEAR, except in COBUILD, whose full-sentence definition ('Someone who suffers from claustrophobia feels very uncomfortable or anxious when they are in small or enclosed places.') requires no genus, and thus no commitment to a conceptual domain. This contrasts with the same dictionary's treatment of agoraphobia ('Agoraphobia is the fear of open or public places'.) - an obvious inconsistency.

Apart from FEAR, another domain, that of FEELING, makes a brief appearance in two definitions. OALD lumps the psychiatric sense of 'an extreme fear of being in a small confined place' with the extended - possibly figurative sense of 'the unpleasant feeling that a person gets in a situation which restricts 
them', separating the two by a semicolon. MW does likewise, except that 'an unhappy or uncomfortable feeling caused by being in a situation that limits or restricts you' is here given the status of a separate second sense. The objective construal, signalled by the use of you above, could easily have been avoided, as demonstrated by the definitions in the remaining dictionaries.

CALD's only example reads: He suffers from claustrophobia so he never travels on underground trains. The majority of LDOCE's (eight) corpus examples do not go beyond illustrating common collocations (suffer from claustrophobia, a feeling of claustrophobia). One is the same as in the agoraphobia entry (It was agoraphobia but felt like claustrophobia); another one (To be here, to have this happening, the claustrophobia of their fatuous intrigues?) is context-dependent to the point of being meaningless.

\section{PANIC ATTACK}

Only CALD and MED have an entry for panic attack. CALD's differentiae cover more symptoms ('your heart beats fast, you have trouble breathing, and you feel as if something very bad is going to happen') and thus provide more information. However, the genus word chosen (period) seems odd, and the whole phrase ('a sudden period of severe anxiety') may be difficult to process. MED's choice of domain (FEELING) is, arguably, better, but the definition, while shorter and simpler ('a sudden very strong feeling of being afraid or worried that makes you unable to breathe'), ends up being slightly vague. One also wonders whether worried is not too weak a description of the feeling of impending doom which is typically part and parcel of a panic attack (see, e.g., Stedman's).

More information pertaining to domain selection can be gleaned from the thesaurus links: CALD cross-refers to the sections Mental and psychiatric disorders and Anxiety and worry - general words, while MED has links to Fear and fright and to Feelings of worry and nervousness. Whether this is enough to help the average user make the connection between, on the one hand, panic attacks and, on the other, anxiety disorder and agoraphobia is less than certain.

However, the main problem in both definitions is objective construal. The use you and your, which places the dictionary user firmly onstage, could easily have been avoided, as someone or a person would have worked in both cases. ${ }^{10}$

Neither dictionary offers examples of use.

\section{EATING DISORDER}

As in the case of depression, there is no agreement among the dictionaries regarding the domain against which eating disorders are best viewed. Two selections (ILLNESS and CONDITION) are repeated, and a new one, DISORDER, appears as well, most likely because it echoes the form of the headword. CALD has the genus mental illness; COBUILD, LDOCE, and MED all have medical condition; OALD plumps for emotional disorder. The choice of genus in CALD, 
LDOCE, and MED is thus consistent with the treatment of the term depression in those dictionaries.

When it comes to differentiae, the domain of NORM is referenced everywhere except in CALD. OALD talks about 'eating habits that are not normal', COBUILD about not eating 'in a normal or healthy way'. LDOCE invokes normality in a subtler way, focusing on the amount of food consumed, but, unfortunately, at the same time resorting to objective construal ('you do not eat a normal amount of food'). The other dictionaries use someone (MED), person (COBUILD), people (CALD), or manage not to make reference to a human subject at all (OALD). On the whole, CALD's definition ('a mental illness in which people eat far too little or far too much food and are unhappy with their bodies') appears to be both the most informative and the least likely to cause discomfort.

COBUILD and MED feature both anorexia and bulimia in their definitions; OALD mentions anorexia; LDOCE has a cross-reference to the bulimia entry.

COBUILD offers one example (Anyone can develop an eating disorder, but young women are most vulnerable.). CALD has three examples 'from literature', one of which (Eating disorders mean eating compulsively because of a distorted body image.) reinforces the information from the definition on the possible aetiology of the disorder. One of the three examples in LDOCE (Thus the compulsive relationship with physical exercise can become effectively part of the spectrum of eating disorder behaviour.) adds important information about eating disorder symptomatology (compulsive exercising) that is not mentioned in any of the definitions.

\section{ANOREXIA (NERVOSA)}

One would expect the domain selected here to be the same as for the superordinate category of eating disorders or, alternatively, that the genus would be eating disorder itself. However, only CALD and OALD are consistent, the former sticking with mental illness, the latter with emotional disorder. COBUILD, LDOCE, MED, and MW agree with CALD that anorexia is an illness (specified as mental in LDOCE and physical and emotional in MW). It may be a moot point whether anorexia is less serious than, say, depression (which, as we remember, OALD defines as a medical condition rather than as an emotional disorder); what is not in doubt is that it is notoriously difficult to treat and all too often has a fatal outcome. ${ }^{11}$ That being the case, further qualification of the illness as serious (in CALD, MED, and MW) is fully justified.

On this occasion, only one dictionary resorts to objective construal (MED: 'a serious illness that makes you want to stop eating').

COBUILD, MW, and OALD point to the fear of becoming fat as the motivation behind anorexic behaviour. None of the dictionaries mentions compulsive exercising (cf., e.g., Taber's) as one of the symptoms. 
CALD, MW, and OALD issue warnings with regard to the effects of anorexia (CALD: 'often resulting in dangerous weight loss'; MW and OALD: 'leading to dangerous weight loss'). The same cannot be said of COBUILD. Making no overt mention of the danger to sufferers' health and emphasizing the thinness resulting from anorexia ('a person has an overwhelming fear of becoming fat, and so refuses to eat enough and becomes thinner and thinner'), the definition might even be (mis)interpreted as a veiled encouragement to food avoidance.

MED and OALD say that anorexia affects mainly young women, a fact highlighted in MW's only example (Anorexia most commonly affects teenage girls and young women). CALD also gives a single example; LDOCE has seven sentences from the corpus, most of them either too context-dependent or too reliant on difficult lexical items (demise, incidence, prevalence) to be of much use.

CALD, MED, MW, and OALD have cross-references to bulimia; additionally OALD cross-refers to orthorexia. OALD also has links to thesaurus sections on Healthy eating habits and Unhealthy eating habits, from where the inquisitive user can arrive at the general domain of HEALTH, with subdomains such as DIET, FITNESS, ILLNESS, MEDICINE, and MENTAL HEATH, a cross-section that gives a pretty good idea of where the anorexia concept is situated.

\section{BULIMIA}

Analogically to anorexia, CALD, COBUILD, LDOCE, MED, and MW all place bulimia within the general domain of ILLNESS (in this instance qualified as mental only in CALD and as physical and emotional in MW), while OALD sticks with emotional disorder. MED and MW, justifiably, describe bulimia symmetrically to anorexia, i.e., as serious. Unlike with anorexia, where both MED and OALD state that the illness affects mainly young women, here it is MW that makes the connection. One cannot help but feel that this is indicative of a lack of co-ordination in the treatment of the two headwords. Another inconsistency is the absence of objective construal in MED - proof, if proof were needed, that it could have been avoided also in the case of anorexia.

When it comes to the level of abstraction, all the dictionaries mention vomiting after eating, and all except COBUILD and MED refer to the large quantities of food consumed. Additionally, CALD and LDOCE highlight the sufferer's lack of control over their food consumption (CALD: 'someone eats in an uncontrolled way'; LDOCE: 'a person cannot stop themselves from eating too much'). Three dictionaries offer some insight into the aetiology of bulimia (COBUILD: ' a person has a very great fear of becoming fat'; MED '... in order to control his or her weight'; MW: '... in order to not gain weight').

Four of the dictionaries have no examples at all. CALD's only example 'from literature' (This is bulimia, the eating disorder discussed earlier.) is distinctly unhelpful. LDOCE gives six sentences from the corpus. Two of those (Unlike anorexia nervosa, bulimia survives by disguise., Often women with bulimia repeat past 
patterns of behaviour in current relationships.) are potentially informative, though both may be too cryptic to be of help to the average user.

CALD, MED, and OALD have cross-references to anorexia. Additionally, CALD has a link to Diets and dieting and to Mental and psychiatric disorders, and OALD to Healthy eating habits and Unhealthy eating habits.

\section{ORTHOREXIA (NERVOSA)}

Two hitherto unencountered domains are invoked here: OBSESSION and DESIRE. This must be because orthorexia is not (yet?) unanimously recognized as a medical problem, as evident from its absence from medical dictionaries. CALD defines it as an obsession, MED as an extreme obsession, and LDOCE as an extreme desire. It cannot go unremarked that while desire is neutral, obsession has negative connotations. However, choosing the latter genus is not necessarily a bad thing if one believes that orthorexia poses a danger to a person's physical and mental well-being. CALD, agreeing with MED and LDOCE about the intensity of the condition, in fact introduces the domain of mental illness in the rest of the definition: 'so extreme it can be considered a mental illness'. OALD rather surprisingly in view of its take on anorexia and bulimia (both defined as emotional disorders) - opts for medical condition.

Only OALD features an example sentence, one that could serve as a selfsufficient definition (A person with orthorexia will be obsessed with defining and maintaining the perfect diet). The same dictionary also has cross-references to anorexia and clean eating.

\section{SELF-HARM}

There is no such entry in MW. The remaining dictionaries feature self-harm either as a verb (COBUILD, OALD), a noun (LDOCE, MED), or both (CALD). Whatever the actual reason behind the choice of grammatical category, it seems that deciding on the verb leads to problems. Verbs encode different meanings than nouns or nominalizations due to differences in construal: the former rely on sequential scanning, the latter on summary scanning (Langacker 2002: 78). Nominalization involves a cognitive operation of reification (Talmy 2006: 78) which, apart from the obvious - construing the referent as an entity rather than a process - imposes more distance between, on the one hand, the speaker/writer and the addressee and, on the other, the situation described. The upshot, in the lexicographic context, is that when defining a verb, there is a danger of putting the dictionary user onstage, which is exactly what happens in three dictionaries,

According to CALD and COBUILD, the verb means 'deliberately hurt yourself', according to OALD, 'deliberately injure yourself'. As with the definitions of panic attack and eating disorder criticized above, here, too, the use of yourself is gratuitously direct. Things look worse still when one reads on: 
'because of mental illness' (COBUILD), 'as a result of having serious emotional or mental problems' (OALD), 'because you have emotional problems or are mentally ill' (CALD). This picture of the dictionary user as a likely self-harmer would have been easiest to avoid in COBUILD, had its full-sentence definition started with 'If someone/a person self-harms ...' rather than 'If you self-harm ...'. In CALD and OALD, where a reflexive pronoun had to be used, oneself would have done the trick. Even assuming that their style-guides require CALD and OALD lexicographers to use yourself, surely cases such as this one warrant a departure from the rule.

It may have been precisely in order to steer clear from yourself that LDOCE and MED chose to present self-harm as a noun. Their definitions are near-identical, the common part reading: 'physical harm that someone (...) deliberately does to their own body, for example (by) cutting their skin'. MED post-modifies the someone ('with emotional problems'), while LDOCE graphically elaborates on how they hurt themselves ('with a knife'). In fact, all the dictionaries mention cutting, which results in a relatively low level of abstraction.

CALD gives a morphosemantic definition (see Geeraerts 2003: 90) of the noun self-harm as act of self-harming. This might be questioned on the grounds that it is the individual act that is profiled here rather than its recurrent nature.

There are no example sentences in LDOCE. COBUILD and MED have one each, with she as the subject; OALD has one, with $I$ in the subject position (As a teenager I was self-harming regularly). CALD gives two examples, one where the self-harmer is a he, the other, more informative one, talking about people (The number of people admitted to hospitals after deliberate self-harm has increased over the last 20 years.).

CALD cross-refers to Mental and psychiatric disorders, MED, rather less insightfully, to Injuries and wounds.

\section{Concluding remarks}

An attempt has been made in this study to employ the notion of construal, in particular its component of focal adjustment, as an ancillary tool for the analysis of dictionary entries. Some differences have been found in the way individual MELDs construe mental health issues, though it is far from certain that they always stem from a conscious decision on the lexicographers' part.

Let us take domain selection first. CALD is the most consistent in its choice of genus, with depression, obsessive-compulsive disorder, anxiety disorder, eating disorder, anorexia, and bulimia all gathered under the umbrella of mental illness (and with anorexia additionally qualified as serious). This seems to genuinely reflect the way the specific conditions are construed. One might perhaps wonder whether the consistency is not achieved at the cost of precision, especially when we compare CALD with OALD, which distinguishes between emotional disorder (for eating disorder, anorexia, and bulimia), mental disorder (for OCD) and medical condition (for depression and orthorexia). However, the OALD cate- 
gories need not be the result of carefully considered choices. The reason behind opting for disorder may simply have been that this lexical element is present in both eating disorder and in the full form of OCD. Why the OALD genus for orthorexia is the same as for depression and not, as one would expect, the same as for anorexia or eating disorder, remains a mystery. On balance, then, the superficially finer distinctions in OALD do not necessarily indicate differences in construal.

When it comes to perspective, objective construal appears at least once in the definitions of the following eight headwords: mental illness (LDOCE), depression (COBUILD, LDOCE), obsessive-compulsive disorder (MED), claustrophobia (LDOCE, MW), panic attack (CALD, MED), eating disorder (LDOCE), anorexia (MED), self-harm (CALD, COBUILD, OALD). In other words, no dictionary manages completely to avoid placing the dictionary user onstage, although, to be fair, MW and OALD have each erred only once. Importantly, a lot of this seems haphazard: why should you appear in the claustrophobia entry but not in the agoraphobia one, why in anorexia but not in bulimia? The easily achievable switch to subjective construal is perhaps the most important practical recommendation following from the present study. Since dictionaries alone do not have the power to eradicate the stigma associated with mental health issues, they should at least avoid implying that the user is, or may be, a sufferer. And yes, a dictionary 'talking to the user' is a commendable project, but the recommendation does not need to be mechanically followed in every single entry.

As regards the level of abstraction, we have seen that the amount of detail given in the definitions varies. When it comes to examples, LDOCE has the most to offer, with CALD's 'examples from literature' coming a close second. A number of the examples, in all the analyzed dictionaries, add little or nothing to the definitions. In the case of names of mental health problems, as with encyclopaedic entries in general, the semantic function of examples is at least as important as their grammatical or stylistic function. Perhaps lexicographers should set themselves more ambitious goals than illustrating usage by listing common collocations (e.g., suffer from $\mathrm{X}$ ) or quoting unedited corpus examples, some of which have zero informative value when taken out of context.

I have approached the topic of this study with the conviction that mental illness, while appropriate as a hyperonym for severe disorders such as psychosis, is best avoided, on the grounds of delicacy, in the case of the conditions discussed here. I was therefore hoping that medical dictionaries might suggest some more suitable, less explicit alternatives for domain selection. That hope remained largely unfulfilled. With some of the conditions, it is the behavioural aspect that comes to the fore, for instance, Mosby's defines eating disorders as a group of behaviours. This is fine when the definition is long and exhaustive, supplying a lot of further detail, but would be less so in the necessarily concise treatment in a general-purpose dictionary. For depression, we get mood disorder (Taber's) and abnormal emotional state (Mosby's). While mood disorder seems spot on, it might be too difficult for the less advanced users of learners' dictionaries. The 
other option, abnormal emotional state, would be more acceptable without the NORM domain being invoked, but then emotional state alone is too vague. Taber's genus social phobia for agoraphobia is, again, exactly right in terms of classification, but of debatable value for a learners' dictionary.

Finally, the reader might expect to be told, on the basis of the above comparison, which dictionary comes out on top. While there is no clear all-round winner, it is CALD that comes closest, definitionwise, to what we might expect from a responsible reference work, attuned to the cognitive and emotional needs of its users. CALD features all the examined entries and exhibits the greatest consistency in domain selection. Except in the case of obsessive-compulsive disorder, it also gives the fullest, most informative definitions.

In sum, appreciating the numerous difficulties and restrictions that MELD writers have to grapple with, and the sheer impossibility of making sure that every semantic field is dealt with as a system of related concepts, I would nonetheless argue that the domain of mental health is too important, especially given the predominantly young audience of learners' dictionaries, to not be treated with special care. Raising mental health awareness may not be the primary goal of pedagogical lexicography, but if it can be achieved with relatively minor modifications to current lexicographic practice - consistent choice of genus terms, sticking with subjective construal, choosing informative examples and editing them where needed - it would be a shame not to pursue it.

\section{Endnotes}

1. The 'still' may be an oversimplification; see Burek Pierce (2010) for an account of how depression (in English) was firmly connected to physical health, and thus managed to avoid stigmatization, until as late as the 17th century. For more background on the interaction between our perception of disease and the language used to talk about it, see Sontag (1978).

2. See https://www.theguardian.com/society/2018/nov/22/why-do-more-young-people-havemental-health-problems.

3. Full dictionary titles and other bibliographical details are given in the References.

4. The centrality of depression, OCD, phobic and eating disorders among contemporary mental health issues has been confirmed time and again by psychopathologists (see, e.g., Ugazio 2013).

5. If there is no main entry for a particular term, but the medical dictionary cross-references it to another entry, the entry is treated as present. This seems to be the most sensible solution in view of the partly onomasiological organization of specialist dictionaries.

6. The earliest OED3 citation for orthorexia comes from 1997.

7. Here, as in many other cases, COBUILD redirects to CED. While it is easy for the user to follow the links, the decision has been made not to include CED in the analysis, since, as a dictionary addressed to native speakers, it is not subject to similar defining restrictions as the other reference works looked at here. Besides, I would like the analysis to be valid also for the print editions of the dictionaries in question.

8. Mild symptoms of anxiety and depression are often associated with social difficulties. She suffers from periods of deep depression, when she locks herself away and will speak to no one for weeks. He has been 
suffering from depression since his wife died last year. During the past few decades, prescription drugs have also been widely used to control the symptoms of depression.

9. Cf. Webster's New World Medical Dictionary: 'Persons with agoraphobia frequently also have panic disorder'.

10. Incidentally, that would also have been in accordance with the practical precepts formulated for COBUILD definitions by Hanks (1987: 126).

11. See, e.g., the Collins Dictionary of Medicine.

\section{References}

\section{A. Dictionaries}

\section{General-purpose}

CED = Collins Online English Dictionary. Glasgow: HarperCollins. Date of access: 1 April 2019.

https://www.collinsdictionary.com/dictionary/english

$C A L D=$ Cambridge Advanced Learner's Dictionary and Thesaurus. Cambridge: Cambridge University Press. Date of access: 1 April 2019.

https://dictionary.cambridge.org/pl/dictionary/english/

COBUILD = Collins COBUILD Advanced English Dictionary. Glasgow: HarperCollins. Date of access: 1 April 2019.

https://www.collinsdictionary.com/dictionary/english/

LDOCE = Longman Dictionary of Contemporary English. London: Pearson. Date of access: 1 April 2019.

https://www.ldoceonline.com/

MED = Macmillan English Dictionary. London: Macmillan Education. Date of access: 1 April 2019. https://www.macmillandictionary.com/

MW = Merriam-Webster's Advanced Learner's English Dictionary. Springfield, Massachusetts: Merriam-Webster, Incorporated. Date of access: 31 August 2019.

http://learnersdictionary.com/

$O A L D=$ Oxford Advanced Learner's Dictionary. Oxford: Oxford University Press. Date of access: 1 April 2019.

https://www.oxfordlearnersdictionaries.com/

OED3 = Oxford English Dictionary online. Date of access: 22 January 2020. https://www-1oed-1com-10186786x12c9.han.amu.edu.pl/

\section{Medical}

Black's Medical Dictionary. 2010. 42nd edition. London: A\&C Black. Collins Dictionary of Medicine. 2007. 4th edition. Glasgow: Harper Collins. Dictionary of Medical Terms. 2004. 4th edition. London: A\&C Black.

Dorland's Illustrated Medical Dictionary. 2012. 32nd edition. Philadelphia: Elsevier Saunders. Melloni's Illustrated Medical Dictionary. 2010. 4th edition. New York/London: Informa Healthcare. 
Mosby's Medical Dictionary. 2013. 9th edition. St Louis: Elsevier Mosby.

Stedman's Medical Dictionary. 2006. 28th edition. Baltimore: Lippincott Williams \& Wilkins.

Taber's ${ }^{\circledR}$ Cyclopedic Medical Dictionary. 2017. 23rd edition. Philadelphia: F.A. Davis.

Webster's New World ${ }^{\mathrm{TM}}$ Medical Dictionary. 2008. 3rd edition. Hoboken, NJ: Wiley Publishing.

\section{B. Other references}

Black, D.W. and J.E. Grant. 2014. DSM-5® Guidebook: The Essential Companion to the Diagnostic and Statistical Manual of Mental Disorders. 5th edition. Washington, DC: American Psychiatric Publishing.

Burek Pierce, J. 2010. Defining Health: Melancholy and Mutation in Early Modern and Modern Medical Dictionaries. Adams, M. (Ed.). "Cunning Passages, Contrived Corridors": Unexpected Essays in the History of Lexicography: 147-163. Monza, Italy: Polimetrica International Scientific Publisher.

Evans, V. 2019. Cognitive Linguistics: A Complete Guide. Edinburgh: Edinburgh University Press.

Geeraerts, D. 2003. Meaning and Definition. Van Sterkenburg, P. (Ed.). 2003. A Practical Guide to Lexicography: 83-93. Amsterdam/Philadelphia: John Benjamins.

Hanks, P. 1987. Definitions and Explanations. Sinclair, J.M. (Ed.). 1987. Looking Up: An Account of the COBUILD Project in Lexical Computing and the Development of the Collins COBUILD English Language Dictionary: 116-136. London: HarperCollins.

Hanks, P. 2013. Lexical Analysis. Cambridge, MA: The MIT Press.

Hart, C. (Ed.). 2019. Cognitive Linguistic Approaches to Text and Discourse: From Poetics to Politics. Edinburgh: Edinburgh University Press.

Kachru, B.B. and H. Kahane (Eds.). 2013 [1995]. Cultures, Ideologies, and the Dictionary: Studies in Honor of Ladislav Zgusta. Berlin: Mouton de Gruyter.

Langacker, R. 1987. Foundations of Cognitive Grammar. Volume 1: Theoretical Prerequisites. Stanford: Stanford University Press.

Langacker, R. 2000. Grammar and Conceptualization. Berlin/New York: Mouton de Gruyter.

Langacker, R. 2002. Concept, Image, and Symbol. Berlin/New York: Mouton de Gruyter.

Langacker, R. 2013. Essentials of Cognitive Grammar. Oxford: Oxford University Press.

Moon, R. 2014. Meanings, Ideologies and Learners' Dictionaries. Abel, A. et al. (Eds.). Proceedings of the XVI EURALEX International Congress: The User in Focus, EURALEX 2014, Bolzano/Bozen, Italy, July 15-19, 2014: 85-105. Bolzano/Bozen: Institute for Specialised Communication and Multilingualism.

Murphy, M.L. 1998. Defining People: Race and Ethnicity in South African English Dictionaries. International Journal of Lexicography 11(1): 1-33.

Norri, J. 2018. Definitions of Some Sensitive Medical Words in Dictionaries of English. International Journal of Lexicography 31(3): 253-273.

Norri, J. 2020. Treatment of Words for Illness and Disability in Monolingual English Dictionaries. International Journal of Lexicography 33(3): 227-250.

Sontag, S. 1978. Illness as Metaphor. https://monoskop.org/images/4/4a/Susan_Sontag_Illness_ As_Metaphor_1978.pdf. 
Swanepoel, P. 2005. On Defining "Imaginary" Beings and Attributes: How Do Lexicographers Cope with Culturally Determined Differences in Beliefs about Cosmology, Ontology and Epistemology? Lexikos 15: 179-195.

Talmy, L. 2006 [1988]. The Relation of Grammar to Cognition. Geeraerts, D. (Ed.). 2006. Cognitive Linguistics: Basic Readings: 69-108. Berlin/New York: Mouton de Gruyter.

Ugazio, V. 2013. Semantic Polarities and Psychopathologies in the Family: Permitted and Forbidden Stories. Translated by Richard Dixon. New York/London: Routledge. 